\title{
Universal and Specific Components in the Article Semantics in Non-Distant Kindred Languages (in Relation to the Material of Parallel Texts)
}

\author{
Irina Timoshenko* \\ Orel State University. Institute of Foreign languages, Orel, Russia
}

\begin{abstract}
The article presents the results of the study of articles' functioning in English and French article analogues in articleless (Russian) language. The conducted scientific work includes the comparison of English and French articles and the peculiarities of their interaction with linguistic and extra-linguistic context by means of contrastive analysis. The semantic invariant of the article common to the considered article languages has been identified, the correlation of this invariant with the ways of referencing the noun in articleless languages has been substantiated. The materials of the article are of practical value for comparative study of languages of different degree of kinship and training of specialized specialists in the field of translation and translation.
\end{abstract}

\section{Introduction}

Comparative study of functioning of parts of speech in non-distant relative languages is an actual direction of linguistic research. Nowadays language and its components are usually considered in the context, and it focuses precisely on the interaction of linguistic units with their contextual environment and extralinguistic reality.

Study of articles' functioning is a relevant and understudied area of research, which has attracted more and more attention of linguists in recent years.

The purpose of the study is to clarify the universal and national specific mechanisms of articles' functioning in non-distant relative languages, to analyze the means of expression of article functions in the Russian language.

According to the purpose of the study, the research objectives are set.

The main research objective is to create the description of the variable usage of articles with nominal groups and clarifying the causes of this variability.

In spite of the fact that in different languages, articles have their own peculiar characteristics, it is possible to conduct cross-language analysis of article forms to identify similarities and differences in articles' functioning. It is also possible to single out the invariant of the article's meaning and carry out the comparison of article forms basing on matching a certain article form with its invariant.

This is evident enough when studying parallel texts in the languages being compared. The most objective results can be obtained by comparing translations from the third articleless language.

One original text allows considering the features of transmitting the noun reference meaning in the original context (in the articleless language) when translating it to an article language in the condition of the possibility of ambiguous interpretation of the original text fragment by the translator.

The study of parallel texts allows to consider the functioning of articles in the context of an identical language situation and to exclude the influence of the human factor. This positively affects the representativeness of the sample, increasing the accuracy of the results of the study, and allows us to consider the peculiarities of the interpreter's perception of the message of the noun expressed in the original language situation as an addressee (see [1]).

When producing a text in a foreign language, the speaker is most often guided by the grammatical rules, which contain the samples of the linguistic norm, learned in the study of the language. It also applies to the choice of articles to indicate the type of reference and other parameters that vary depending on the particular language. A speaker in a foreign language consciously applies a practical skill which has been developed during the repeated use of grammar patterns containing articles. A native speaker of a language does not follow any specially learnt rules and is not normally conscious of the reasons of his choice of certain linguistic units. It may be stated that in this case there is a peculiar linguistic reflex, which allows the native speaker not to waste his cognitive resources on the process of selection of a necessary lexical unit, phrase or grammar structure. The native speaker has some subconscious processes, which automatize the selection process, activated. This is illustrated most clearly by the choice of the article by a native-speaker translator.

There has not been any special synthesis study devoted to the subject of comparative study of the peculiarities of articles' functioning in non-distant relative languages by now. Yet, there is a historiographical basis for such contrastive analysis which includes the works on the theory of reference [2, $3,4,5,6,7,8]$, the researches in the language philosophy and psychology $[9,10]$, and the scientific

* Corresponding author: timoshenko@outlook.com 
papers which deal with certain aspects of the article in relation to specific languages $[11,12]$. Due to the fragmented nature of the study of various aspects of the topic, some issues remain poorly researched, and this problem requires a special scientific study.

The hypothesis of this research is that the article system functioning in English and French is conducted by the common patterns: the articles in both English and French have a common invariant which conveys the information about the noun (or nominal group) type of the reference to extra-linguistic reality object. In specific article forms, which correspond in one of the languages to a certain invariant, some extra and peculiar to a separate language system component of the meaning can find its expression.

\section{Methods and materials}

The main methods used in this scientific study are chronological, statistical, retrospection, and actualization. The application of the epistemological and logical principles of the methodology made it possible to carry out a comprehensive analysis of the functioning of the articles in conjunction with objective language conditions and subjective factors affecting this process. Objectives of the study led to the use of the comparison of methods and typology which allowed one to reveal the general and specific features in the functioning of articles in non-distant relative languages.

The choice of non-distant relative languages for contrastive analysis, on the one hand, is due to the need to examine the functioning of the article as a pointer to the type of reference of a name in the systems of an article with a nonidentical structure, and, on the other hand, it is due the possibility of studying ways of referencing using a uniform formula of a prepositive article. The uniform design of the article component of the nominal group (noun) makes it possible to exclude the completely grammatical conditionality of the discrepancies in indicating the type of reference of the noun or nominative group.

The material of the study was parallel translations from Russian into English [II, III] and French [IV, V] of chapters I and XXV of the novel "Master and Margarita" by M.A.Bulgakov [I], performed by Diane Bergin and Catherine Tiernan O'Connor, Hugh Aplin, Claude Ligny and Françoise Flamant. We analyzed two translations into English and two translations into French, each performed by professional translators who are native speakers of the target language.

The choice of material for scientific work is not arbitrary and is caused by the existence of more than one translation of the novel as in English and French, which allows one to produce not only a cross-language, but also an intralinguistic analysis and improve the accuracy of the research results. The consideration of two translations into English and two translations into French reduces the probability of an erroneous choice of article and, consequently, inadequate transfer of reference relations contained in the source text.
The comparison of the functioning of the system of articles in different languages has been repeatedly undertaken by both Russian and foreign researchers. In these researches, article and its features received different descriptions. In particular, it is proposed to consider the article as a component of the statement from the standpoint of the theory of reference.

V.G. Gak defines the phenomenon of reference as "the correlation of the linguistic sign with the objects of extralinguistic reality in the process of communication" $[13$, p. 96], and the article - as a pointer to the nature of the reference of the noun in each separate text. He emphasizes that "a name or a nominal group are referential if they correspond to a certain object or group of objects selected from this class of objects and represented in the minds of the speakers; they are not referential if they do not correspond with any individualized object, but with the class as a whole, or with the sign of these objects" [13, p. 96].

In the study proposed to your attention, the transfer of the referential meaning of a name (nominal group) is taken as the main purpose of the article in speech.

In the comparative analysis conducted in this study, the author makes an attempt to construct an integral theory capable of describing the features of the operation of the article for conveying the reference of a noun and establishing possible causes for the occurrence of mismatches between the use of articles for the transfer of reference relations perceived from one initial communicative situation. The object which the noun establishes referential relations with is contained in the extralinguistic reality and is perceived by the translator through the corresponding name and its context in the text in the original language.

A number of revealed mismatches in the use of the article is due to the discrepancies in the interpretation of the original language situation. The possibility of a different interpretation of the original text was studied, in particular, by E.S. Kubriakova, considering the problem of 'figurative representations' as the main reason for the mismatches to appear: "the representation of an object to consciousness must preserve the features of similarity, and in this sense it corresponds to" the world as it is ", but because of the limitations of such similarity, it turns out to be both a unit processed by our consciousness and, of course, different representations can differ significantly in the degree of their similarity to the original " [14, p. 65]. In the process of real communication, differences in figurative representations are compensated by refinements, as a result of which the speakers come to a common understanding of the subject of speech.

The translator, when translating text fragments containing unambiguous determinacy of the type of reference, is forced to rely solely on their own understanding of the noun reference and the corresponding object, which can lead to mismatches in the use of articles in identical speech situations. One of the founders of discursive analysis, E. Benveniste, considering discourse as "the functioning of language in living communication" [7], indicates that a discursive act is a separate communicative event occurring in a specific 
communicative context, and the utterance is in fact "speech given by the speaker" [7].

For considering the functioning of articles in the text the description of the article system proposed by F.A. Litvin is used $[12,15]$, where the article is understood as a separate part of speech, having its own lexical meaning, the main purpose of which in the language is the expression of the obligatory lexical meaning of the noun in a non-morphological way [12: p. 89]. It should be noted that, within this description, the zero article is understood as meaningful absence of one of the ... physical forms of the article "[15: p. 75], and is differentiated from any absence of the article and these cases are not considered as homonymy. On this occasion F.A. Litvin points out that the absence of the article is seen in situations where a "pointing at the set is sufficient regardless of its representation by the elements of the set" [15: p. 76]. In further work on the project, the authors of the proposed project have additionally introduced a clarification on the absence of the article in the constructions, where the other type of determinant indicates the type of reference of the name [1]. The zero article in the conditions of "mandatory pointing at the noun reference" carries out such "indication in the conditions of the absence of one of the other two indicators." [15: p. 76]

In the F.A. Litvin's functional description of the invariant of the definite article, it is presented as a "selection from the class", since the definite article indicates that "the set whose name the noun is in the language is represented in the situation nominated in this act of speech, by one or a set of elements of the set, -th) from the general series (for abstract nouns, the element is the manifestation of the nominal of the noun) "[12: p.89]. In other words, individualization is taken as an invariant of the lexical meaning of a definite article [15: p. 75]. The invariant of the indefinite article is regarded as a classification or, in other words, "referring to a class". Here, 'classification' is "an indication of the denotation by a noun of a representative of a class, one of the set, but not allocated from it" [15: p. 75]. That is, "an indefinite article is a sign that the denomination of a noun is represented in the referent of a given speech statement as an element of a set as possessing attributes that are differential for the whole set." [16: p. 76] The zero-article invariant in the classification accepted in this paper is presented as having the significance of generalization, that is, fulfilling the function of "naming the class" [14: p. 90], indicating the type of reference for nomination as the name of a "set without identifying its elements; it can be a noun in the singular, referring not to the element of the set, but to the set as a whole, or (in English and German) the plural form of the noun "[15: p. 76]. The zero article indicates that "a noun's referent is a class as a set, and not any element of this set, that is, the noun is the name of the class as a whole, undivided; this also applies to the meaningful absence of the article in the plural form of the noun." [15: p. 76] Within such a functional description, the article's presentation is based on its ability to indicate the nature of the relation of the actual set and the common set.
When comparing English to French, it is found that the invariant is preserved and other parameters and functions are added. In English, the article doesn't express any information about a name except the referential meaning, and in French the article also indicates the number, gender and value of the discretion / non-discretion parameter of the named set. A discrete set in this work is an infinite countable set, and an undiscrete set is an infinite countable set. This leads to mismatches of the article choices in cross-language translations. The indication of discretion / non-discretion is associated with the characteristics of the perception of the world that are characteristic of the French linguistic consciousness, but a partitive article conveying the corresponding meaning can be presented based on its nominative properties. In this case, it becomes possible to consider it as having an invariant with the meaning "class naming".

In the absence in the original text of a specific indication of the type of reference, an ambiguous interpretation of the original context is possible, that at the textual level is manifested in mismatches in the choice of the article, and at the level of cognitive processes is manifested in the influence of the subjective component of the linguistic personality on the perception of the original text and on the referential choice.

\section{Results}

Held in the study of comparative logical analysis allows formulating the following conclusions.

The main purpose of the article is to indicate the type of reference of names and nominal groups. Фe the same time (depending on the language) the article may express additional parameters of the noun defined by this article.

The article is a separate part of speech, which is characterized by its own meaning, purpose, patterns of functioning. Each separate article form corresponds with one article invariant.

National specifics can influence the way how article forms correspond with their invariants. In the French language there is a partitive article representing an extra category of discretion/non-discretion, which corresponds to the invariant of the definite article. Language as the dynamic and developing system allows varying of the norm in the use of the articles for pointing out the referential meaning, thus in several cases there can be mismatches in the interpretation of the original text fragment and in the use of an article to represent the referential meaning, which was understood from the source text. These mismatches happen due to the referential choice which the translator has to make on his own and, plus, because the category of reference is a hidden linguistic category in Russian.

The conducted research does not cover all the questions connected with the problem of studying the linguistic units, which express the referential meaning. So, there may be further researches on developing the complex model of article functioning using the methods of computer linguistics. There also can be a further study of articles functioning in non-kindred languages and 
study of various determinants that can express the referential meaning of a noun.

\section{Discussion}

More than 700 contexts have been recorded to analyze the functioning of articles on the basis of the method of continuous sampling. During the analysis, a sample of names and nominal groups was made, which included all nouns and equivalent nominative groups, except for units with determinants other than the article (deictic, indefinite and quantitative pronouns). In total, 4855 nouns and nominal groups were recorded. These nominees (nominative groups) make up 1,282 units that are analyzed according to the stated criteria and are subject to comparison and subsequent analysis, of which 1012 complete tetrads, 269 are triads (in one translation there is no material for comparison). Out of these, 912 are matches, 370 are mismatches.

The presence and significant prevalence of coincidences (about $70 \%$ of the entire sample) confirms the assumption that the basis of the article's functioning in comparable languages is similar principles, and the mechanisms of functioning are based on the general semantic invariant of the article, which can be called universal for the languages under research.

The presence of mismatches in a statistically significant number (more than $30 \%$ of the total number of analysed elements) suggests that in the absence of specific instructions for the type of reference in the source language translator who is both the addressee and the addressor, relying on his own interpretation of the original text fragment, offers the reader his own understanding of what type of the reference is pointed at in the context. So, the translator makes an independent referential choice. It can lead to the mismatches in the use of articles in identical language situations. Due to the fact that it is impossible to observe the course of this process directly, the researcher can only consider the translator's activity, visible in the course of the comparative analysis, using the means of the target language in order to transfer the values of the components of the source text in the absence of feedback to the author of the original, that is, when translating the written text.

Three types of coincidences and discrepancies were identified: 1) complete matches (all translators used the same article); 2) intralinguistic mismatches (three translators used the same article, the fourth translation used another article, or there were discrepancies within each of the monolingual pairs of translations); 3) interlingual mismatches (intralinguistic coincidence of the articles do not coincide with each other).

In the studied translations of the chapters, there are 294 interlingual and 196 intralinguistic mismatches recordedout of which 88 sre in English and 108 are in French.

Each of the types of mismatches can be caused by one of three factors that influence their occurrence. The first one is the different interpretations of the reference type conveyed in the original text. For example, in Chapter I,

(1) В нашей стране атеизм никого не удивляет, // "In our country atheism comes as no surprise to anyone," // "In our country atheism surprises no one, //"Dans notre pays, l'athéisme n'étonne personne, // Dans notre pays, l'athéisme n'étonne personne,

there is the mismatch атеизм // atheism // atheism // l'athéisme // l'athéisme. In the traslations into French the original referential meaning is identified as "selection from the class" what is shown by the usage of the definite article. In translations into English, the original referential meaning is understood as "naming the class" which is marked by zero article in translations.

The second factor, which can influence the translator in his choice, is the preference of different directions on the different reference types. Thus, for example, in Chapter 1:

u по мере того, как Михаил Александрович забирался в дебри, // and as Mikhail Alexandrovich ventured into that maze, // and the deeper Mikhail Alexandrovich clambered into the thickets // Et, à mesure que Mikhaïl Alexandrovitch s'enfonçait dans un labyrinth // et plus Mikhaïl Alexandrovitch s'aventurait dans des dédales

a single intralinguistic mismatch is caused by the possibility of understanding the noun "дебри" as having the reference meaning "selection from the class" and naming the particular object which Mikhail Alexandrovich was venturing into ( 2 translations) and at the same time, the reference meaning of this noun can be understood as "referring to a class" (1 translation).

The third reason for the mismatches to occur is the consideration of the language situation from different points of view and the application of the differing principles of interpretation of the original indication of the referential meaning of the name. For example, in Chapter 1 of the novel:

(2) Гражданин ростом в сажень // The man was seven feet tall // A citizen almost seven feet tall, // Ledit citoyen était d'une taille gigantesque - près de sept pieds // Le citoyen mesurait une bonne sajène de haut.

This context conveys 1 mismatch in the use of articles. In two translations, the language situation is viewed from the standpoint of the speaker, who knows what citizen is talking about, defining this object as being selected from the class, which is transmitted with the help of a definite article. In one translation into English, the context is viewed from the standpoint of a listener who does not have enough information about which object the citizen refers to, and defines the type of reference as "referring to the class", using an indefinite article with the corresponding value of the invariant.

\section{Conclusion}

There is some common for all languages invariant of the article, which receives a concrete embodiment in the art form. In some languages, the article may express in addition the numerical, generic and other attributes of 
the noun in addition to the referential meaning. The national specifics of the article system can influence how the article forms relate to invariants.

Each of the article forms corresponds to one of the invariants of the article, indicating the nature of the relationship of the named object, represented as a subset, with an entire set.

Language allows for variation in the norm in using articles to refer to a referential meaning, and in some cases, it may lead to mismatches in the article use because of the interpretation of the original language situation. In an articleless language, reference is a hidden category, and the referential meaning is transmitted through a variety of means, for which an indication of the type of reference of the name is an additional function. When translating from unarticulated language to an article translator, the hidden language category is translated into explicit, based on its understanding of the original referential relations.

\section{Sources}

I. M..A Bulgakov, Master and Margarita (Moscow: AST, 2001)

II. Bulgakov M., The Master and Margarita. Trans. by Hugh Aplin, (London: One World Classics, 2008)

III. Bulgakov M., The Master and Margarita, Trans. by Diana Burgin and Katherine Tiernan O'Connor, (London: Picador, 1997).

IV. Boulgakov M., Le Maître et Marguerite. Trad. par Françoise Flamant, (P.. Éditions Gallimard, 2004)

V. Boulgakov M., Le Maître et Marguerite, trad. par Claude Ligny. (P., Robert Laffont, 2012)

\section{References}

1. I.V. Timoshenko, Functioning of articles in English and French (on the material of parallel texts), "Typology of Morphosyntactic Parameters 2016". Issue 3, Institute of Linguistics RAS/MSPU, URL: http://ossetic-studies.org/tmp2016/ru/gensling (2016)

2. Linsky L., Reference and referents (New York, 1967)

3. E.V. Paducheva, Utterance and its Reference to Reality (M.: Nauka, 1985)

4. G. Frege, Logic and phylosophical works, (Novosibirsk, 2008)

5. A.D. Shmelev, The Russian language and reality, Languages. Semiotics. Culture, Languages of Russian cultures (M., 2002)

6. Bally Ch. La pensée et la langue, Bulletin de la Société linguistique de Paris (Paris,1922)

7. E. Benveniste, Problèmes de linguistique générale, (P. : N. R. F., Bibliothèque des sciences humaines, 1966)

8. J.S. Mill, The Collected Works of John Stuart Mill, (Toronto/L.,1963)
9. W.V.O. Quine, Ontological Relativity and Other Essays (New York, Columbia University Press., 1969)

10. M. A. Shelyakin, Language and Man (M., Flinta, 2012)

11. I.N. Kuznetsova, Ways of describing the grammatical system of language by the example of the representation of the article in basic French grammars (M., PSTBI, 2002)

12. F.A. Litvin, Society \& Man 2 (2014)

13. V.G. Gak, Theoretical grammar of French (2000)

14. Kubryakova E.S. News of the Academy of Sciences, Series of Literature and Language 3(56) (1997)

15. F.A. Litvin, Problem of theory, practice and didactics of translation 16(II) (N.Novgorod, 2013) 